\begin{tabular}{|c|c|c|}
\hline \multirow[b]{2}{*}{ FVCF } & $\begin{array}{l}\text { International Journal of Current Research in } \\
\text { Biosciences and Plant Biology }\end{array}$ & \\
\hline & Volume $5 \bullet$ Number 6 (June-2018)・ISSN: 2349-8080 (Online) & \\
\hline $\begin{array}{l}\text { EXCELLENT } \\
\text { PUBLISHERS }\end{array}$ & Journal homepage: www.ijcrbp.com & 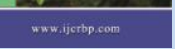 \\
\hline
\end{tabular}

Original Research Article

doi: https://doi.org/10.20546/ijcrbp.2018.506.005

\title{
Yield Comparison of Soil and Soilless Grown Strawberry
}

\author{
Abdulameer I. Narriman*, \$ and Bahram Kh. Mohammed
}

College of Agriculture, University of Kirkuk, Kirkuk, Iraq

*Corresponding author; \$ Part of M. Sc., thesis.

\begin{tabular}{|c|c|}
\hline Article Info & \multirow{4}{*}{ 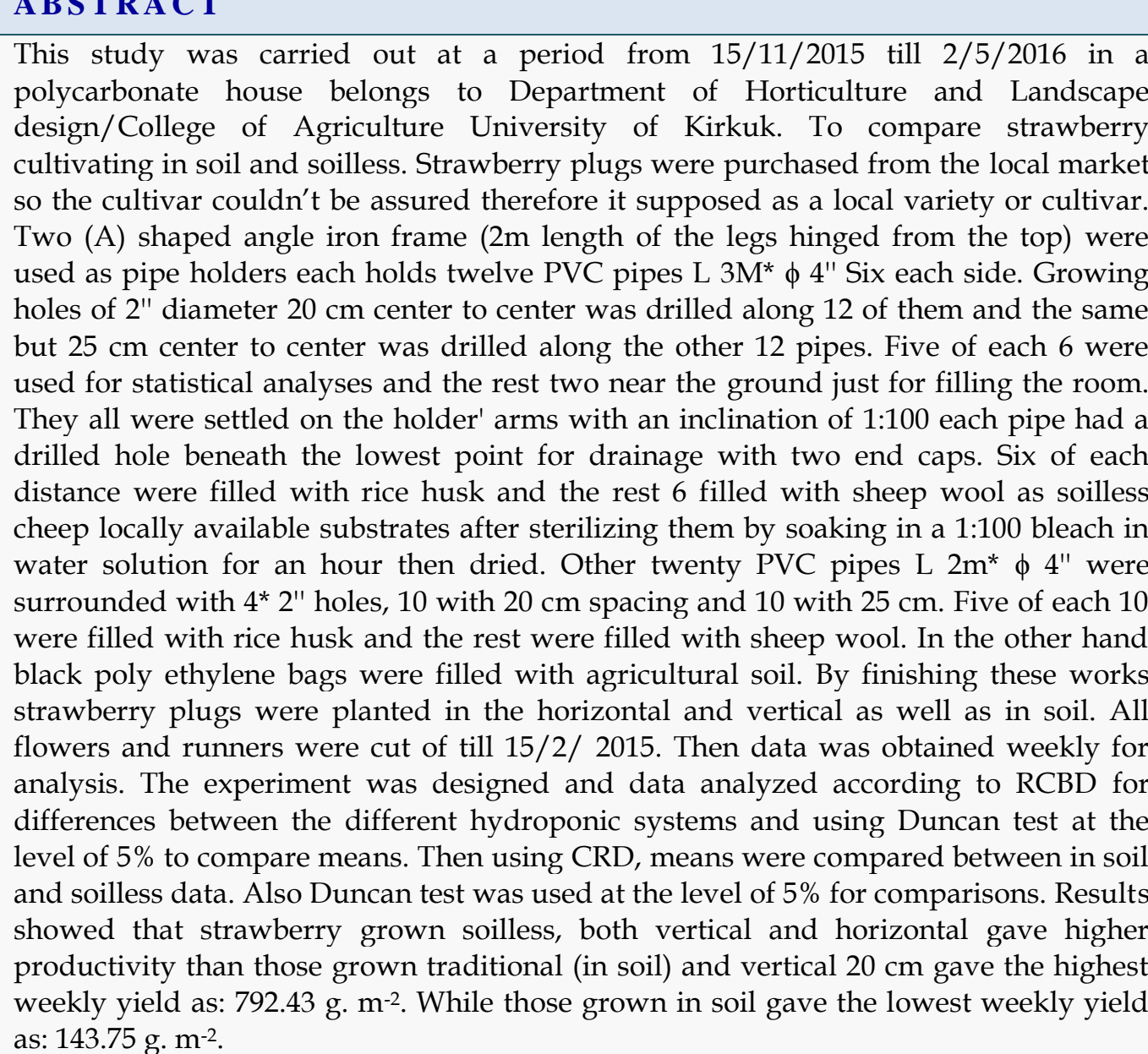 } \\
\hline $\begin{array}{l}\text { Date of Acceptance: } \\
28 \text { May } 2018\end{array}$ & \\
\hline Keywords & \\
\hline $\begin{array}{l}\text { Agriculture soil } \\
\text { Fragaria species } \\
\text { Hydroponic systems } \\
\text { Rice husk } \\
\text { Sheep wool }\end{array}$ & \\
\hline
\end{tabular}




\section{Introduction}

Increasing of the world population from less than 1 billion to more than 7.3 billion since 1800 till nowadays, and expecting it approaches 9.7 billion on 2050 is very dramatic and shocking fact, especially for those concerned in insuring foods for these hungry mouths. Of course agronomists are the first ones bear the responsibility of this issue. They are working all over the world to discover new food resources and maintaining the existing ones, developing and hybridizing plants and edible animals, improving their disease resistance, environment tolerance. Also finding out new methods and techniques to increase their productivity and decrease their production costs. One of these techniques is soilless agriculture (UN DESA, 2015).

So, what is soilless agriculture? How it could be defined? Is it useful and applicable anywhere any time? Which crops could be produced soilless? These and many other questions could be asked. This work tries to find out some answers for these questions and look if it is beneficial or not for the farmers in our region, keeping in mind that they are almost not or half educated.

Aeroponics, aggregate media culture, NFT, flood and ebb, hydroponics etc. All represent deferent soilless agriculture techniques or hydroponics (Benton, 2005). The common term hydroponics will be used in this paper interchangeably with the term soilless agriculture, just like in the popular language or even in most of scientific references, referring to soilless agriculture.

Strawberry is a hybrid plant belongs to the Rosaceae family, the Genus Fragaria L. consists more than 20 species each has many subspecies and hundreds of varieties. Its delicious test, nice flavor, and fragrant aroma made it one of the most beloved fruits, and for its heart shaped, red color people used it as a symbol for Venus the Goddess of love. (Trinklein, 2012). Strawberry is classified in some places; like Egypt; as a vegetable because of its plant's small size and annually vegetation.
(Agricultural researches center, Ministry of agriculture, Egypt, 2003).

- Water shortage caused by many natural or political reasons, in general, specifically in Iraq. Plus wasting it by irresponsible and unreasonable usage, especially for irrigation by old ways, causing earth salinity and ecosystem pollution by drained fertilizers, etc.

- Soilless agriculture works successfully in other countries, does it work beneficially in Iraq using local resources? If not, then why? Is that a solvable issue?

- Strawberry is a good economic crop worldwide; could it be a popular one here in Iraq?

The above reasons and many other ones alike are enough to persuade researchers to think seriously in doing such researches to find out some applicable solutions for these issues. And in case of success or getting good results; encourage field agricultural engineers to spread these ideas among farmers or agricultural investment companies.

\section{Materials and methods}

\section{Experiment execution location}

The experiment was carried out in a fiberglass house in the College of agriculture University of Kirkuk, during the 2015-2016 growth season. 4" PVC pipes and accessories like pipe caps, drain nozzles and tubes, plastic growing bags., etc. were purchased from the local markets. Strawberry refrigerated plugs also were purchased from a local supplier so it couldn't be assure the cultivar. Thus it will be assumed as a local cultivar.

\section{Substrates used for soilless culture}

Rice hulk and sheep wool were purchased as cultivating medium for soilless culture, as local available, cheap alternatives of the common used medium such as perlite, vermiculite, coconut coir, etc. because of their specifications of porosity and water holding, low density, low chemical reaction with fertilizers and so. 


\section{Preparing planting pipes}

First of all 4" PVC pipes were cut as $24 * 3 \mathrm{~m}$ length for horizontal system, 20 of them were for data collecting and the four lowest ones just for filling the empty seats on the (A) shaped pipe holders. $20 * 2 \mathrm{~m}$ length for the vertical ones. Then 2" holes were drilled along 12 of the $3 \mathrm{~m}$ pipes with a distance of 25 $\mathrm{cm}$, i.e. 12 holes per pipe, same diameter holes were drilled in the rest 12 of $4 * 2$ " holes drilled around 10 of the $2 \mathrm{~m}$ pipes with a distance of $20 \mathrm{~cm}$ between each set of fours, the rest 10 was drilled with a distance of $25 \mathrm{~cm}$ between each set of fours.

Also $4 * 0.5 \mathrm{~mm}$ holes drilled between every two sets of 4 holes and passed two steel wires diagonally to carry a plastic handmade strainer.Then 12 horizontal pipes were fixed on each (A) shape iron holder 6 on each side, $100 \mathrm{~cm}$ between legs on the floor and $60 \mathrm{~cm}$ service pathway between holders with $1: 100 \mathrm{~cm}$ inclination of the pipes for easy drainage, and the vertical ones hanged with $80 \mathrm{~cm}$ spacing within rows and $100 \mathrm{~cm}$ pathway between rows, i.e. plant density per meter in the horizontal pipes was: (estimating half of the area occupied with the pipe holder plus half of the pathway for each 6 pipes)

The work's main aim was testing a simple, open, aggregate soilless technique using rice husk and sheep wool as locally available, cheap, substrates to study their efficiency as aggregate soilless media by growing a plant in. The chosen test plant was strawberry. The second aim is studying this crop, its cultivations, economical importance, environmental requirements, and its productivity when it is grown hydroponically and conventionally. Then comparing the results we got from soilless with results got from traditional in soil grown strawberry to get a fair judgment on them.

Both sheep wool and rice husk were soaked in a 1:100 bleach in water solution about an hour for sterilizing, then placed on mulching films till dryness, then half of the vertical pipes and half of the horizontal ones were filled with sheep wool and the rest halves filled with rice hulks.
At this time, earth of a high tunnel plastic greenhouse was prepared i.e. plowed, furrowed as $100 \mathrm{~cm}$ in-between, compost added, etc. for conventional planting, in the same time plastic growing bags were filled with soil as spare in case of failure of the conventional planting, unfortunately that expectation happened, the reasons may due to many factors such as: the earth of the greenhouse was translocated from a non agricultural area, deferent soil borne pathogens; the earth was not fumigated with methyl bromide, the area was used before as a parking garage for the college's vehicles. So for the in soil planted plugs we were compelled to depend on the polyethylene black bags filled with agricultural soil for comparison, keeping in mind, plant density and the way of planting as recommended in the booklet of strawberry (Habeeb and Aal Ferawn, 2013) for data collection for statistical analyses.

On December 2015, in wool, in husk strawberries as well as both in soil ones; grown based and using black polyethylene bags; were planted. 5:1000 final dilution of 30:10:10 NPK + TE solution used during the first month to firtigated the soilless strawberries twice a day, and twice a week for the in soil planted ones. $\mathrm{pH}$ regulated to be 5.5-6.5 using citric acid $\left(\mathrm{C}_{6} \mathrm{O}_{7} \mathrm{H}_{8}\right)$. Then 20:20:20 NPK $+\mathrm{TE}$ was used. All flowers, runners, dry leaves were eliminated till February 15th, Data collection executed as the following:

- Date of flowering: $1^{\text {st }}$ mature flower in the replicate.

- Date of ripening: Full coloring of the fruit.

- Fruit size: Water displacement technique.

- Fruit weight: Using a digital scale. 0.0001$120.0000 \mathrm{~g}$

- Number of fruits per plant: Averaging the counted fruits per replicate.

- Leaf area: Photography of leaves on A4 paper, cutting the pictures of the leaves, weighing them and comparing their weight with the weight of a full color printed A4 
paper (known area), the ratio represented the area of the leaves.

- Number of leave per plant: Simple counting.

- TSS: Portable refractometer

- $\mathrm{pH}$ of the fertigation solution: Portable $\mathrm{pH}$ meter.

- $\mathrm{pH}$ of the fruit abstract: Bench type $\mathrm{pH}$ meter.

\section{Plant density calculation for the soilless ones}

15plants/pipe*12pipes $/(3 \mathrm{~m} * 1.8 \mathrm{~m})=33.3$ plants $/ \mathrm{m}^{2}$

12plants/pipe*12pipes $*(3 \mathrm{~m} * 1.8 \mathrm{M})=26.6$ plant $/ \mathrm{m}^{2}$

While the density in the vertical $20 \mathrm{~cm}$ space ones was:

( 4 plants $* 10$ sets per pipe) / $(0.8 \mathrm{~m}$ within the row $*$ $1.00 \mathrm{~m}$ between rows $)=$

$4 * 10 / 0.8 * 1.00=50$ plants $/ \mathrm{m}^{2}$ and

( 4 plants $* 8.0$ sets per pipe) / $(0.8 \mathrm{~m}$ within the row $* 1.00 \mathrm{~m}$ between rows) $=40$ plant $/ \mathrm{m}^{2}$

This way all plants were exposed to sunlight, no plant left a heavy shade on others, with a comfortable servicing area. And for the in soil ones plant density was $10 / \mathrm{m}^{2}$.

\section{Experimental design and analyses of data}

The completely randomized design (CRD) was used in designing the experiments between hydroponic and in soil , but split split plot design Completely Randomized Block Design (CRBD), with two factors and three replicates, and uses Duncan's Multiple Range 0.05 to compare between means of the experiment treatments. All data were analyzed by (SAS 2001) program.

\section{Results and discussion}

To compare the properties effected by the two ways; studied in this research; of cultivating strawberries conventionally in soil and hydroponically or soilless a CRD experiment was executed and data were analyzed using SAS 2001 statistical program, then; means of the studied properties were tested by Duncan test at the level of $5 \%$. Table 1 shows that fruit juice $\mathrm{pH}$ and leaf area and size of the fruit have not affected significantly at a level of $5 \%$, as well as the ripeness period and TSS. While number of fruits per plant a week and total weight of fruits varied significantly they were higher as figures and as letters both; hydroponically than in soil. Two properties gave higher values in soil grown plants than soilless ones, these were: number of leaves per plant. And weight of fruits was heavier in soil grown than those of soilless grown plants.

Table 1. Effects of cultivating media (soil \& soilless) on some properties of strawberry.

\begin{tabular}{lrr}
\hline Media properties & Soilless & In soil \\
\hline Fruit $\mathrm{pH}$ & 3.124 & 3.101 \\
Leaf area & 92.64 & 98.63 \\
No. of fruits/plant & $49.14 \mathrm{a}$ & $26.38 \mathrm{~b}$ \\
No. of leaves/plant & $18.214 \mathrm{~b}$ & $19.387 \mathrm{a}$ \\
Fruit size cm & 17.672 & 17.229 \\
Time from flower till ripeness (day) & 25.327 & 25.636 \\
Yield per plant (g) & $459.19 \mathrm{a}$ & $287.50 \mathrm{~b}$ \\
TSS (Brix) & 5.361 & 5.381 \\
Fruit weight (g) & $9.344 \mathrm{~b}$ & $10.896 \mathrm{a}$ \\
\hline
\end{tabular}

Means followed by the same letters in a column do not differ by Duncan test at a level of 5\% probability and those followed by different letters differ at the same test and same level. 
Table 2. Effect of cultivating system (vertical \& horizontal) hydroponic and spacing on number of fruits per plant.

\begin{tabular}{llcc}
\hline $\begin{array}{l}\text { Position of the pipes } \\
\text { (factor A) }\end{array}$ & \multicolumn{2}{l}{ Space between plants $(\mathbf{H})$ and set of $\mathbf{4}$ plants (V). (factor B ) } & Effect of (A) \\
\hline Horizontal & $\mathbf{2 0 ~} \mathbf{~ c m}$ & $\mathbf{2 5} \mathbf{~ c m}$ & $1.509 \mathrm{a}$ \\
Vertical & $1.376 \mathrm{a}$ & $1.641 \mathrm{a}$ & $1.502 \mathrm{a}$ \\
Effect of (B) & $1.527 \mathrm{a}$ & $1.478 \mathrm{a}$ & \\
\hline
\end{tabular}

Means followed by the same letters in a column do not differ by Duncan test at a level of 5\% probability and those followed by different letters differ at the same test and same level

Table 3. Effect of cultivating system (vertical \& horizontal) hydroponic and spacing on the total weight of the fruits during the total fruiting period.

\begin{tabular}{llcc}
\hline $\begin{array}{l}\text { Position of the pipes } \\
\text { (factor A) }\end{array}$ & \multicolumn{2}{l}{ Space between plants (H) and set of $\mathbf{4}$ plants (V). (factor B ) } & Effect of (A) \\
\hline Horizontal & $\mathbf{2 0 ~} \mathbf{~ c m}$ & $\mathbf{2 5} \mathbf{~ c m}$ & $368.96 \mathrm{~b}$ \\
Vertical & $289.26 \mathrm{c}$ & $448.66 \mathrm{~b}$ & $549.42 \mathrm{a}$ \\
Effect of (B) & $633.94 \mathrm{a}$ & $464.90 \mathrm{~b}$ & \\
\hline
\end{tabular}

Means followed by the same letters in a column do not differ by Duncan test at a level of 5\% probability and those followed by different letters differ at the same test and same level

Table 4. Effect of media on weekly harvested strawberry.

\begin{tabular}{llll}
\hline Media characters & Harvested from 1 pipe $(\mathbf{g})$ & $\begin{array}{l}\text { Harvested from 5 pipes } \\
(\mathbf{g})\end{array}$ & ${\text { Total }(\mathbf{g}) / \mathbf{m}^{2}}^{\mathbf{2}}$ \\
\hline Rice hulks & 216.94 & 1084.7 & 483.09 \\
$(20) \mathrm{cm}(\mathrm{H})$ & $\mathrm{c}$ & $\mathrm{c}$ & $\mathrm{b}$ \\
Rice hulks & 215.36 & 1076.8 & 478.57 \\
$(25) \mathrm{cm}(\mathrm{H})$ & $\mathrm{c}$ & $\mathrm{c}$ & $\mathrm{b}$ \\
Rice hulks & 633.94 & 3169.7 & 792.43 \\
$(20) \mathrm{cm}(\mathrm{V})$ & $\mathrm{c}$ & $\mathrm{a}$ & $\mathrm{a}$ \\
Rice hulks & 464.90 & 2324.5 & 581.12 \\
$(25) \mathrm{cm}(\mathrm{V})$ & $\mathrm{b}$ & $\mathrm{b}$ & $\mathrm{b}$ \\
In soil $(25) \mathrm{cm}$ & 230.00 & 1150.00 & 143.75 \\
8 plant $/ \mathrm{m}^{2}$ & $\mathrm{c}$ & $\mathrm{c}$ & $\mathrm{c}$ \\
\hline
\end{tabular}

Means followed by the same letters in a column do not differ by Duncan test at a level of 5\% probability and those followed by different letters differ at the same test and same level.

Table 2 shows that even that there is no difference according to Duncan $5 \%$ between horizontal $20 \mathrm{~cm}$ and $25 \mathrm{~cm}$ in number of fruits per plant but it is clear that $25 \mathrm{~cm}$ distance gave a slightly higher 
fruits per plant, as well as the vertical system. And that may due to the bigger root rooming.

Total fruit weight (yield) was highly affected by the distance between plants within the same system and between the two systems as shown in Table 3 for the horizontal system; considering the other factors; rooming affected positively on the yield, while in the vertical system it affected inversely on the yield. In the other hand it is very clear that the vertical system exceeded the horizontal in the yield. Root size and sufficient rooming.

Table 4 summarizes significant differences between weekly grams of strawberries harvested via using deferent medias (in soil, soilless) also between the same media soilless but in vertical and horizontal technique and the third parameter is distance between plants (plants $/ \mathrm{m}^{2}$ ) and this is the soul of this research.

From Table 4, it is very clear that using $20 \mathrm{~cm}$ distance vertical soilless gave the heights weight weekly harvested and as the total.

\section{Conclusion}

From this research we concluded that Soilless culture could be one of the solutions of water shortage all over the world. It is beneficial economically in the long term. It is eco-friendly agriculture. Soilless cultures in general; in spite of the system type; increase the plant density, so if one gets the same yield per plant as in soil cultivation or even less than it; the yield per square meter will be grater in the soilless culture pass over other reasons. That was clear in our results.

\section{References}

Agricultural Researches Center, 2003. Ministry of Agriculture, Egypt Bulletin No. 780/2003 (In Arabic).

Benton, J. Jr., 2005. Hydroponics A Practical Guide for the Soilless Grower, Third Edn. 2005.

Habeeb, H., Aal Firaon, A., 2013. Strawberry. Directorate of Horticulture/Ministry of Agriculture, Iraq (In Arabic).

SAS, 2001. Statistical Analysis System (2001) User's Guide: Statistics, Version 8.2. SAS Institute, NC, USA.

Trinklein, D., 2012. Strawberry, A Brief History published: May 21, University of Missouri Division of Plant Science (573) 882-9631 trinkleind@missouri.edu.

UN DESA, 2015. United Nations, Department of Economic and Social Affairs, Population Division (2015). World Population Prospects: The 2015 Revision, Key Findings and Advance Tables, Working Paper No. ESA/P/WP.241.

\section{How to cite this article:}

Narriman, A. I., Mohammed, B. Kh., 2018. Yield comparison of soil and soilless grown strawberry. Int. J. Curr. Res. Biosci. Plant Biol. 5(6), 52-57. doi: https://doi.org/10.20546/ijcrbp.2018.506.005 